\title{
On a truncated accelerated plan for two component parallel systems under ramp-stress testing using masked data
}

\begin{abstract}
Several studies on design of Acceptance Life Test (ALT) focused on a subsystem (single system) totally ignoring its internal design. In most cases, it is not always possible to identify the components that cause the system failure or the cause can only be identified by a subset of its component resulting in a masked observation. This paper therefore investigates into development of ramp-stress accelerated life testing for a high reliability parallel system that consist two dependent components using masked failure data. This type of testing may be very useful in a twin-engine plane or jet. A ramp-stress results when stress applied on the system increases linearly with time. A parallel system with two dependent components is taken with dependency modeled by Gumbel-Hougaard copula. The stress-life relationship is modeled using inverse power law and cumulative exposure model is assumed to model the effect of changing stress. The method of maximum likelihood is thereafter used for estimating design parameters. The optimal plan consists in finding optimal stress rate using D-optimality criterion by minimizing the reciprocal of the determinant of Fisher information matrix. The projected plan is also explained using a numerical example and sensitivity analysis carried out. This formulated model can help control engineers to obtain reliability estimates quickly of high reliability products that are likely to last for several years.
\end{abstract}

Keywords: accelerate, life test, ramp-stress, gumbel-hougaard copula, masked data, fisher information matrix, d-optimality criterion, dependent components

\section{Introduction}

After production process has been carefully controlled up till the finished products, high reliability products of modern times have to be subjected to accelerated life test to detect early failures. This also helps the manufacturer to obtain timely reliability estimates about his products and live on in today's competitive market. Such products may be subject to different stress loading schemes. Such stress schemes include: constant-stress, step-stress, progressive-stress and their various combinations depending upon how they are to be used in service and other limitations both theoretical and practical. ${ }^{1,2}$ A rampstress results when stress applied linearly increases with time. A stress can be applied under fully accelerated environmental conditions in which all the test specimens are tested under accelerated condition or partially accelerated environmental conditions where they are tested both under normal and accelerated conditions. ${ }^{3,4}$

Several accelerated life test plans under different stress loading schemes have been devised in several literatures. ${ }^{5,6}$ Nevertheless, all these plans are meant for a single system (i.e, a sub- system) with its internal configuration totally ignored. In many cases, it is not always probable to identify the component that caused the system failure or the cause of failure can only be identified by a subset of its component. ${ }^{7}$ An observation is said to be masked when event cause of the system failure is not known except that it is as a result of some subset of the component of the system have used the exact maximum likelihood estimation of life time distribution of the component in the series system using masked data. ${ }^{8-10}$ have used the Bayes estimation of component reliability from masked system-life data. ${ }^{89}$ have extended the results of ${ }^{11}$ to a three component series system of exponential distribution. Fan \& $\mathrm{Hsu}^{12}$ has used the masked interval data in the series system of exponential components. Formulation of a rampstress ALT plan for a parallel system with two dependent components
Volume 2 Issue 5 - 2018

\author{
Braimah Joseph Odunayo \\ Department of Mathematics, Ambrose Alli University, Nigeria
}

Correspondence: Braimah Joseph Odunayo, Department of Mathematics, Faculty of physical Sciences, Ambrose Alli University, Ekpoma, Edo State, Nigeria, Email Ojbraimah20I4@gmail.com

Received: August 14, 2018 | Published: September 24, 2018 but without masking has been studied by Srivastava \& Savita. ${ }^{13}$ This paper centered on formulation of a ramp-stress ALT plan for a system with parallel configuration in the presence of masked failure data. Such a testing may prove to be useful in a twin-engine plane or jet. A parallel system with two dependent components is taken with dependency modeled by Gumbel-Hougaard copula. The optimal stress rate is obtained using D-optimality criterion. A numerical example has also been used to explain the projected plan and sensitivity analysis has been carried out to examine its robustness.

\section{The model}

In this section the model for formulation of a ramp-stress ALT plan for a system with parallel pattern in the presence of masked failure data is developed and its life distribution function and likelihood function are obtained.

\section{Assumptions}

i. Gumbel-Hougaard copula comprising two Weibull reliability marginals is used to model the dependency between two components.

ii. The two components of the system cannot fail simultaneously (at the same time)

iii. Failed parallel systems are not replaced during the test.

iv. The occurrence of masking is independent of the failure cause and time.

v. The effect of changing stress is modeled by the linear cumulative exposure model (Nelson, 1990).

vi. The stress applied to test units is continuously increased with constant ramp rate $\boldsymbol{k}$ from zero. 
vii. The inverse power law holds for stress-life relationship, i.e,

$$
\eta(\mathrm{s}(\mathrm{t}))=\mathrm{e}^{\mu}\left(\frac{\mathrm{S}_{0}}{\mathrm{~S}(\mathrm{t})}\right)^{\alpha}
$$

Where $\mu$ is the characteristics of the product and $\alpha$ is the shape parameter, $\mathrm{s}(\mathrm{t})$ is a linear function of time in ramp-stress.

\section{Test procedure}

The reliability testing procedure is as follows:

A. $\mathrm{N}$ independent and identical parallel systems are put to test and their failure times along with the cause of failure are recorded. An observation is said to be masked if its corresponding cause of failure cannot be recorded.

B. The test is terminated when all the systems fail.

\section{Parallel system}

A parallel system fails if all the components fail. The configuration of a parallel system with two components is shown in Figure 1.

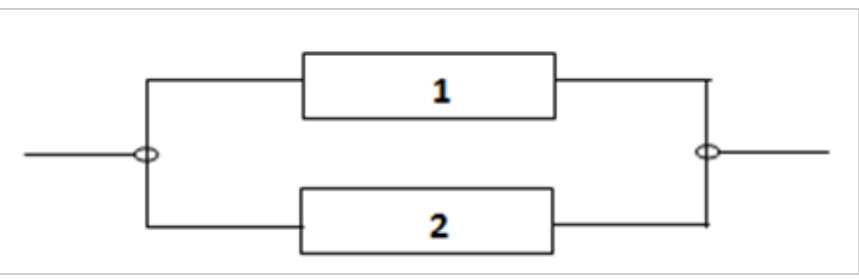

Figure I Parallel System.

\section{Copula function}

The dependency existing between the marginal random variables in bivariate and multivariate distributions is described by a copula. ${ }^{1}$ The copula describes the way in which the marginals are linked together on the basis of their association.

Suppose $\mathrm{X}_{1}$ and $\mathrm{X}_{2}$ are two random variables and let $\mathrm{G}_{1}\left(\mathrm{x}_{1}\right)$ and

$$
\mathrm{g}\left(\mathrm{t}_{1}, \mathrm{t}_{2}\right)=\mathrm{e}^{-\left(\left(\frac{\mathrm{t}}{\mu_{1}}\right)^{\beta_{1}} \alpha+\left(\frac{\mathrm{t}}{\mu_{2}}\right) \beta_{2 \alpha}\right)^{\frac{1}{\alpha}}} \beta_{1} \beta_{2}\left(\frac{\mathrm{t}_{1}}{\mu_{1}}\right)^{\beta_{1}} \alpha+\left(\frac{\mathrm{t}_{2}}{\mu_{2}}\right)^{\beta_{2 \alpha} \alpha} \times \frac{\left(\left(\frac{\mathrm{t}_{1}}{\mu_{1}}\right)^{\beta_{1}} \alpha+\left(\frac{\mathrm{t}}{\mu_{2}}\right)^{\beta_{2 \alpha}}\right)^{-2+\frac{1}{\alpha}\left(\left(\frac{\mathrm{t}_{1}}{\mu_{1}}\right)^{\beta_{1}} \alpha+\left(\frac{\mathrm{t}_{2}}{\mu_{2}}\right)^{\beta_{2 \alpha}}\right)^{\frac{1}{\alpha}+\alpha-1}}}{\mathrm{t}_{1} \mathrm{t}_{2}}
$$

Where $\mathrm{t}_{1} \geq 0, \mathrm{t}_{2} \geq 0, \mu_{1}>0, \beta_{1}>0, \mathrm{i}=1,2$ and $\alpha \geq 1, \mu_{\mathrm{i}}$ are scale parameters, $\beta$ are shape parameters and $\alpha$ is the association between the two variables. From the linear cumulative model, the joint reliability function of the parallel system under ramp-stress scheme is given as:

$$
\hat{\mathrm{F}}\left(\mathrm{t}_{1}, \mathrm{t}_{2}\right)=\hat{\mathrm{G}}\left(\mathrm{E}\left(\mathrm{t}_{1}\right), \mathrm{E}\left(\mathrm{t}_{2}\right)\right)
$$

Where $\hat{G}(\ldots)$ is the underlying bivariate Weibull reliability function with assumed scale parameter taken to be one (1).

$$
\mathrm{E}(\mathrm{t})=\int_{0}^{\mathrm{t}} \frac{1}{\mu(\mathrm{S}(\alpha))} \mathrm{d} \alpha
$$

Equation above is the cumulative harm (damage) model at t. Therefore, the joint cumulative distribution (reliability) function and joint probability (failure) density function respectively of the system under ramp-stress loading are given as:
$\mathrm{G}_{2}\left(\mathrm{x}_{2}\right)$ be their respective marginal reliability functions. If $\mathrm{H}\left(\mathrm{x}_{1}, \mathrm{x}_{2}\right)$ are their joint reliability function. Therefore, according to Sklar's theorem, there exists a copula reliability function $\mathrm{C}\left(\mathrm{x}_{1}, \mathrm{x}_{2)}\right.$ such that for all that $\left(\mathrm{x}_{1}, \mathrm{x}_{2}\right)$ in the defined array:

$$
\overline{\mathrm{H}}\left(\mathrm{x}_{1}, \mathrm{x}_{2}\right)=\mathrm{C}\left(\hat{\mathrm{G}}_{1}\left(\mathrm{x}_{1}\right), \hat{\mathrm{G}}_{2}\left(\mathrm{x}_{2}\right)\right)
$$

Amongst the Gumbel-Hougaard copula is defined as:

$$
\mathrm{C}_{\mu}(\mathrm{a}, \mathrm{b})=\mathrm{e}^{-\left(-\log _{\mathrm{e}}[\mathrm{a}]\right)^{\mu}+\left(-\log _{\mathrm{e}}[\mathrm{b}]^{\mu}\right)^{\frac{1}{\mu}}}
$$

Where $1 \leq \mu \leq \infty$ characterizes the relationship between the two variables. Gumbel-Hougaard copula is uni-parametric and symmetrical.

\section{Reliability function for bivariate-weibull distribution}

The reliability function for Bivariate Weibull distribution is obtained by using Weibull reliability marginals in Gumbel-Hougaard reliability function. Using equation (3) and assumption (i), equation (4) is arrived at:

$$
\hat{G}\left(t_{1}, t_{2}\right)=e^{-\left(\left(\frac{t_{1}}{\mu}\right) \beta_{1} \alpha+\left(\frac{t_{2}}{\mu}\right) \beta_{2} \alpha\right)^{\frac{1}{\alpha}}}
$$

Where $\mathrm{t}=$ testing time, $\mu=$ quality parameter, $\beta=$ risk and $\alpha=$ shape parameter. ${ }^{16}$

\section{The bivariate weibull reliability function for ramp- stressed data}

The Bivariate Weibull reliability function of a parallel system using Gumbel-Hougaard copula (Escobar and Meeker 1995) is given by:

$$
\hat{G}\left(t_{1}, t_{2}\right)=e^{-\left(\left(\frac{t_{1}}{\mu}\right) \beta_{1} \alpha+\left(\frac{t_{2}}{\mu}\right) \beta_{2} \alpha\right)^{\frac{1}{\alpha}}}
$$

The bivariate joint probability density function is given as:

$$
\mathrm{F}\left(\mathrm{t}_{1}, \mathrm{t}_{2}\right)=\mathrm{e}^{-\left(\left(\int_{0}^{\mathrm{t}_{1}} \frac{1}{\mu(\mathrm{S}(\mathrm{a}))} \mathrm{da}\right) \beta_{1} \mathrm{a}+\left(\int_{0}^{\mathrm{t}_{2}} \frac{1}{\mu(\mathrm{S}(\mathrm{a}))} \mathrm{da}\right) \beta_{2} \mathrm{a}\right)^{\frac{1}{\alpha}}}
$$

Therefore,

$$
\begin{array}{r}
\mathrm{F}\left(\mathrm{t}_{1}, \mathrm{t}_{2}\right)=\mathrm{e}^{-\left(\left(\left(\frac{\mathrm{t}_{1}}{\phi_{1}}\right) \beta_{11} \alpha+\left(\frac{\mathrm{t}_{2}}{\phi_{2}}\right) \beta_{22} \alpha\right)^{\frac{1}{\alpha}}\right)} \\
\left.\mathrm{F}\left(\mathrm{t}_{1}, \mathrm{t}_{2}\right)=\mathrm{e}^{-\left(\left(\left(\frac{\mathrm{t}_{1}}{\phi_{1}}\right) \beta_{11} \alpha+\left(\frac{\mathrm{t}_{2}}{\phi_{2}}\right) \beta_{22} \alpha\right)\right.}\right)_{\beta_{1} \beta_{2}\left(\frac{\mathrm{t}_{1}}{\phi_{1}}\right) \beta_{11} \alpha\left(\frac{\mathrm{t}_{2}}{\phi_{2}}\right) \beta_{22} \alpha} \\
\times \frac{\left(\left(\frac{\mathrm{t}}{\phi_{1}}\right) \beta_{1} \alpha+\left(\frac{\mathrm{t}}{\phi_{2}}\right) \beta_{2} \alpha\right)^{-2+\frac{1}{\alpha}\left(\left(\frac{\mathrm{t}_{1}}{\phi_{1}}\right) \beta_{11} \alpha+\left(\frac{\mathrm{t}_{2}}{\phi_{2}}\right) \beta_{22} \alpha\right)^{\frac{1}{\alpha}}+\alpha-1}}{\mathrm{t}_{1} \mathrm{t}_{2}}
\end{array}
$$


Where

$$
\begin{aligned}
& \phi_{\mathrm{i}}=\left(\mathrm{e}^{\gamma_{0}}\left(\frac{\mathrm{S}_{0}}{\mathrm{k}}\right) \gamma_{\mathrm{i}\left(1-\gamma_{\mathrm{i}}\right)}\right)^{\frac{1}{1+\gamma_{\mathrm{i}}}} \text { is the scale parameter, } \\
& \beta_{\mathrm{ii}}=\beta_{\mathrm{i}}\left(1+\gamma_{\mathrm{i}}\right)
\end{aligned}
$$

\section{The D-optimality}

The D-optimality criterion is used in minimizing the reciprocal of the determinant of Fisher information matrix, the Fishers smaller value of the determinant corresponds to a higher (joint) precision of the estimators of $\alpha, \beta .{ }^{14}$

\section{Likelihood function}

This section deals with the case of the complete system but masked data. Likelihood for a parallel system is developed for two dependent components. Suppose we consider a sample of n-systems each consisting of two dependent components in parallel. Suppose Ti is the life time of system $\mathrm{I}$ and $T_{i j}$ is the life time of component $\mathrm{j}$ in system $i, i=1,2 \ldots \ldots$ and $j=1,2$, then

$$
\mathrm{T}_{\mathrm{i}}=\max \left(\mathrm{T}_{\mathrm{i} 1}, \mathrm{~T}_{\mathrm{i} 2}\right)
$$

The probability that the system fails due to component 1 , when $0 \leq \mathrm{t}_{1}<\infty$ is obtained as:

$$
\begin{aligned}
& \mathrm{P}\left[\mathrm{T}_{\mathrm{i} 2} \leq \mathrm{t}_{\mathrm{i}}, \mathrm{t}_{\mathrm{i}}<\mathrm{T}_{\mathrm{i} 1} \leq \mathrm{t}_{\mathrm{i}}+\Delta \mathrm{t}_{\mathrm{i}}\right]=\mathrm{F}_{\mathrm{T} 1}\left(\mathrm{t}_{\mathrm{i}}+\Delta \mathrm{t}_{\mathrm{i}}\right)-\mathrm{F}_{\mathrm{T} 1, \mathrm{~T} 2}\left(\mathrm{t}_{\mathrm{i}}, \mathrm{t}_{\mathrm{i}}\right) \\
& =\mathrm{F}_{\mathrm{T} 1}\left(\mathrm{t}_{\mathrm{i}}\right)-\mathrm{F}_{\mathrm{T} 1, \mathrm{~T} 2}\left(\mathrm{t}_{\mathrm{i}}, \mathrm{t}_{\mathrm{i}}\right)
\end{aligned}
$$

As $\Delta \rightarrow 0$ and since $\mathrm{F}_{\mathrm{T} 1}$ is absolutely differentiable,

$$
\begin{aligned}
& \overline{\mathrm{F}}_{\mathrm{T} 2}\left(\mathrm{t}_{\mathrm{i}}\right)-\overline{\mathrm{F}}_{\mathrm{T} 1, \mathrm{~T} 2}\left(\mathrm{t}_{\mathrm{i}}, \mathrm{t}_{\mathrm{i}}\right) \\
& \overline{\mathrm{F}}_{\mathrm{T} 2}\left(\mathrm{t}_{\mathrm{i}}\right)-\overline{\mathrm{F}}_{\mathrm{T} 1, \mathrm{~T} 2}\left(\mathrm{t}_{\mathrm{i}}, \mathrm{t}_{\mathrm{i}}\right)
\end{aligned}
$$

Therefore, $\mathrm{L} \infty-\frac{\partial}{\partial \mathrm{t}_{1}}\left(\overline{\mathrm{F}}_{\mathrm{T} 1, \mathrm{~T} 2}\left(\mathrm{t}_{1}, \mathrm{t}_{2}\right)\right) \mathrm{I}_{\mathrm{t}_{1}=\mathrm{t}_{\mathrm{i}}, \mathrm{t}_{2}=\mathrm{t}_{\mathrm{i}}}$

Also, the probability that the system fails due to component 2 , when $0 \leq t \leq \infty$ is obtained as:

$P\left[\mathrm{~T}_{\mathrm{i} 1} \leq \mathrm{t}_{\mathrm{i}}, \mathrm{t}_{\mathrm{i}}<\mathrm{T}_{\mathrm{i} 2} \leq t_{i}+\Delta t_{i}\right]=\mathrm{F}_{\mathrm{T} 2}\left(\mathrm{t}_{\mathrm{i}}+\Delta \mathrm{t}_{\mathrm{i}}\right)-\mathrm{F}_{\mathrm{T} 1, T 2}\left(\mathrm{t}_{\mathrm{i}}, \mathrm{t}_{\mathrm{i}}\right)$

$=\mathrm{F}_{\mathrm{T} 2}\left(\mathrm{t}_{\mathrm{i}}\right)-\mathrm{F}_{\mathrm{T} 1, T 2}\left(\mathrm{t}_{\mathrm{i}}, \mathrm{t}_{\mathrm{i}}\right)$

As $\Delta t \rightarrow 0$ and since $F$ is absolutely differentiable,

$=1-\mathrm{F}_{\mathrm{T} 1}\left(\mathrm{t}_{\mathrm{i}}\right)-\overline{\mathrm{F}}_{\mathrm{T} 1, T 2}\left(\mathrm{t}_{\mathrm{i}}, \mathrm{t}_{\mathrm{i}}\right)$

$\overline{\mathrm{F}}_{\mathrm{T} 1}\left(\mathrm{t}_{\mathrm{i}}\right)-\overline{\mathrm{F}}_{\mathrm{T} 1, T 2}\left(\mathrm{t}_{\mathrm{i}}, \mathrm{t}_{\mathrm{i}}\right)$

Therefore, $\mathrm{L} \infty-\frac{\partial}{\partial t_{2}}\left(\overline{\mathrm{F}}_{\mathrm{T} 1, T 2}\left(\mathrm{t}_{1}, \mathrm{t}_{2}\right)\right) \mathrm{I}_{\mathrm{t} 1=\mathrm{ti}, \mathrm{t} 2=\mathrm{ti}}$

\section{The log-likelihood (L)}

The log-likelihood of an $n$ parallel system is as given below:

$$
\begin{aligned}
\mathrm{L}=\prod_{\mathrm{S}_{\mathrm{i}}=1}^{\mathrm{n}_{1}}\left(-\frac{\partial}{\partial \mathrm{t}_{1}}\left(\overline{\mathrm{F}}_{\mathrm{T} 1, \mathrm{~T} 2}\left(\mathrm{t}_{1}, \mathrm{t}_{2}\right)\right)\right) \times \prod_{\mathrm{S}_{\mathrm{i}}=2}^{\mathrm{n}_{2}}\left(-\frac{\partial}{\partial \mathrm{t}_{2}}\left(\overline{\mathrm{F}}_{\mathrm{T} 1, \mathrm{~T} 2}\left(\mathrm{t}_{1}, \mathrm{t}_{2}\right)\right)\right) \\
(17) \quad \times \prod_{\mathrm{S}_{\mathrm{i}}=1}^{\mathrm{n}_{1}+\mathrm{n}_{2}}\left(-\frac{\partial}{\partial \mathrm{t}_{1}}\left(\overline{\mathrm{F}}_{\mathrm{T} 1, \mathrm{~T} 2}\left(\mathrm{t}_{1}, \mathrm{t}_{2}\right)\right)-\frac{\partial}{\partial \mathrm{t}_{2}}\left(\overline{\mathrm{F}}_{\mathrm{T} 1, \mathrm{~T} 2}\left(\mathrm{t}_{1}, \mathrm{t}_{2}\right)\right)\right)
\end{aligned}
$$

where $\mathrm{n}$ is specified by the control engineer (experimenter).

$$
\begin{aligned}
\mathrm{L}=\sum_{\mathrm{S}_{\mathrm{i}}=1}^{\mathrm{n}_{1}} \log \left(-\frac{\partial}{\partial \mathrm{t}_{1}}\left(\overline{\mathrm{F}}_{\mathrm{T} 1, \mathrm{~T} 2}\left(\mathrm{t}_{1}, \mathrm{t}_{2}\right)\right)\right) \times \sum_{\mathrm{S}_{\mathrm{i}}=2}^{\mathrm{n}_{2}} \log \left(-\frac{\partial}{\partial \mathrm{t}_{2}}\left(\overline{\mathrm{F}}_{\mathrm{T} 1, \mathrm{~T} 2}\left(\mathrm{t}_{1}, \mathrm{t}_{2}\right)\right)\right) \\
\quad \times \sum_{\mathrm{S}_{\mathrm{i}}=1}^{\mathrm{n}_{12}} \log \left(-\frac{\partial}{\partial \mathrm{t}_{1}}\left(\overline{\mathrm{F}}_{\mathrm{T} 1, \mathrm{~T} 2}\left(\mathrm{t}_{1}, \mathrm{t}_{2}\right)\right)-\frac{\partial}{\partial \mathrm{t}_{2}}\left(\overline{\mathrm{F}}_{\mathrm{T} 1, \mathrm{~T} 2}\left(\mathrm{t}_{1}, \mathrm{t}_{2}\right)\right)\right)
\end{aligned}
$$

\section{Simulated of parameter estimation}

The Maximum Likelihood Estimates of $\rho, \rho, \beta$ and $\beta$ are obtained using R statistical software.

The simulation is carried out following [15].

The algorithm is given below:

i. Select $\mathrm{n}$ units and put them to test.

ii. Specify the masking level $\rho$.

iii. Calculate $\mathrm{n}_{12}$ such that ${ }_{12} \approx\left(\frac{\rho}{n} * 100\right)$.

iv. Arbitrarily select a random sample of size $\mathrm{n}$ from the system life time, and the set of component causing the system failure $\left(\mathrm{t}_{1}, \mathrm{~s}_{1}\right), \ldots,\left(\mathrm{t}_{\mathrm{n}}, \mathrm{s}_{\mathrm{n}}\right)$.

These random samples are generated following the steps below:

i. Generate $n_{12}$ observations using the system cumulative (i.e, product's lifetime) distribution, which is known as time to failure.

ii. Generate $\mathrm{n}-\mathrm{n}_{12}$ observations using the system cumulative distribution, and determine Si for each i, $\left(\mathrm{i}=1,2, \ldots, \mathrm{n}-\mathrm{n}_{12}\right)$, which gives the set of observations where the cause of system failure is known.

\section{Maximum likelihood estimates (MLE) of the design parameters}

The ML estimates of the design parameters obtained using simulated data in table 1 are:

$$
\rho_{1}=-2.2, \rho_{2}=0.5, \beta=0.35 \text { and } \beta=0.24
$$

Table I Simulated data

\begin{tabular}{lll}
\hline $\begin{array}{l}\text { System } \\
\text { No. }\end{array}$ & Time to failure $\left(t_{\mathrm{i}}\right)$ & $\begin{array}{l}\text { Component failure- } \\
\text { cause } \\
\left(\mathbf{S}_{\mathrm{i}}\right)\end{array}$ \\
\hline I. & 0.0516 & $(2)$ \\
2. & 0.1504 & $(1,2)$ \\
3. & 0.1944 & $(1,2)$ \\
4. & 1.2604 & $(1)$ \\
5. & 3.1649 & $(1,2)$ \\
6. & 5.437 & $(2)$ \\
7. & 5.5425 & $(1)$ \\
8. & 8.5725 & $(2)$ \\
9. & 10.0166 & $(1)$ \\
10. & 10.9509 & $(2)$ \\
\hline
\end{tabular}

In selecting an optimum test plan, there is a need to estimate the design parameters $\rho \quad \rho \quad \beta \quad$ and $\beta$. These estimates at times may $01, \quad 02, \quad 11, \quad 12$ 
affect the values of the resulting decision variables significantly. Therefore, their incorrect choice may result in poor estimate of the design constant stress. Therefore, it is significant to carry out a sensitivity analysis to evaluate the robustness of the resulting Acceptance Life Test plan.

Sensitivity analysis helps to identify the design parameters $\rho, \rho, \beta$ and $\beta$ which need to be estimated with care to avoid the risk $12, \quad 2$ of obtaining wrong solutions. An Acceptance Life Test plan is said to be robust if a small departure in any has no effect in relative change in the optimal plan.

The percentage deviations (PD) of the optimal settings are obtained as $\mathrm{PD}=\left(\frac{\left|\mathrm{T}^{* *}-\mathrm{T}^{*}\right|}{\mathrm{T}^{*}}\right) \times 100$, where $\mathrm{T}^{*}$ is obtained with the given design parameters and $\mathrm{T}^{* *}$ is obtained when the parameter is miss-specified.

Table 2 illustrates the optimal test plans for various deviations from the design parameter estimates. The results explain that the optimal setting of $\mathrm{T}$ is robust to the small variance from baseline parameter estimates.

Table 2 Sensitivity Analysis for changes in design parameters

$$
\rho_{1=-3.45,}^{\rho}=20, \beta_{2=0.65, S_{0}}=0.35 \text { and } \beta_{2}=0.25, n=10, n=3 \text { and } \alpha=0.8
$$

\begin{tabular}{cllll}
\hline Parameter & $\%$ & $\mathbf{K}$ & $\mathbf{T}^{* *}$ & Percent deviation (\%) \\
\hline$\beta$ & $-5 \%$ & 1.75 & 0.000574 & 3.6526 \\
${ }_{1}$ & $+5 \%$ & 1.74 & 0.000596 & 7.6891 \\
$\beta_{2}$ & $-5 \%$ & 1.78 & 0.000583 & 5.3500 \\
$\beta$ & $+5 \%$ & 1.67 & 0.000587 & 5.9500 \\
$\rho_{0}$ & & & & \\
0 & $-5 \%$ & 1.57 & 0.000585 & 5.5979 \\
$\rho$ & $+5 \%$ & 2.024 & 0.000585 & 5.5872 \\
0 & $-5 \%$ & 1.59 & 0.000589 & 4.9225 \\
$\rho$ & & & & \\
1 & $+5 \%$ & 1.81 & 0.000581 & 6.2877 \\
1 & & & &
\end{tabular}

\section{Conclusion}

This paper carefully determines a ramp-stress Acceptance Life Test for accelerated environmental conditions for a high reliability parallel system consisting of two dependent mechanism (components) using masked failure data. Such an experiment (testing) may be very useful in a two-engine plane or jet. Conclusively, a simulation study (using $\mathrm{R}$ ) is used to illustrate the method developed. The sensitivity analysis results prove that the proposed plan is better for a small departure from baseline parameters.

\section{Acknowledgements}

None.

\section{Conflict of interest}

Author declares that there is no conflict of interest.

\section{References}

1. Nelson RB. An Introduction to Copulas. Springer Science and Business Media, Inc. New Jersey. 2006.

2. Elsayed EA. Reliability Engineering Addison-Wesley, Massachusets. 1996.

3. Bhattacharya GK, Soejoeti ZA. Tampered Failure Rate Model for StepStress Accelerated Life Test. Commun, Statist Theor Meth. 1989. p. 1627-1643.

4. De Groot MH, Goel PK. Bayesian Estimation and Optimal Designs in Partially Accelerated Life Testing. Naval Res Logist Quart. 1979;26(2):223-235.

5. Srivastava PW, Shukla R. Optimum log-logistic step-stress model with censoring. International Journal of Quality \& Reliability Management. 2008;25(9):968-976.

6. Srivastava PW, Gupta T. Optimum Time-Censored Modified RampStress ALT for The Burr Type XII Distribution with Warranty: A Goal Programming. International Journal Approach, of Reliability. Quality and Safety Engineering, 2015;22(3):23-25.

7. Guo H Szidarovszky F, Niu P. Estimating component reliability data. Reliability and Maintainability Symposium. 2013. p. 312-320.

8. Usher JS, Hodgson TJ. Maximum likelihood analysis masked system of life data. IEEE Trans. Reliability, 1988;37(5):550-555.

9. Lin DK, Usher JS, Guess FM. Exact likelihood maximum estimation using masked system-life data. IEEE Trans Reliability. 1993;42(4):631635 .

10. Lin DK, Usher JS, Guess FM. Bayes estimation of component-life data. IEEE Trans. Reliability. 1996;45(2):233-237.

11. Miyakawa M. Analysis of incomplete data. IEEE Trans Reliability. 1984;33:293-296.

12. Fan TH, Hsu TM. Accelerated life tests of a series system with masked interval data under Exponential lifetime Distribution. IEEE Tran Reliability. 2012;45:233-237.

13. Srivastava PW, Savita. Design-Stress of Accelerated RampLife Test Plans for a Parallel System with two dependent components. International Journal of Performability Engineering. 2016;12(3):241-248.

14. Escobar LA, Meeker WQ. Planning accelerated life tests with two or more experimental factors. Technometrics. 1995;37(4):411-427.

15. Sarhan AM, Usher JS, Guess FM. Estimators for Reliability Method Model Using Dependent Masked Data System Life Test. IEEE Trans. Reliability. 2007;56(2):312-320.

16. Johnson NL, Kotz S. Continuous Multivariate Distributions. New York: John Wiley \& Sons; 1972. 